\title{
Relação entre Qualidade da Auditoria e Conservadorismo Contábil nas Empresas Brasileiras
}

\section{Resumo}

Pesquisadores têm feito uso, ao longo do tempo, de um conjunto de muitos e distintos atributos, quando da tentativa de explicar a relação entre a qualidade da informação contábil e outras variáveis, especialmente no âmbito do mercado de valores mobiliários. Nesse contexto, o conservadorismo é apontado como uma das principais características de qualidade da informação contábil, a qual pode resultar de fatores presentes no ambiente contábil como, por exemplo, sistema jurídico, conjunto de normas contábeis, entre outros. A auditoria de demonstrações contábeis, tendo em vista a justificativa que sustenta a necessidade do trabalho, finda por influenciar a qualidade da informação contábil. Pesquisas anteriores, quando investigaram a relação entre auditoria independente e qualidade da informação contábil, usaram, normalmente, uma única característica da auditoria, como, por exemplo, o tamanho da firma de auditoria. Este trabalho teve por objetivo verificar a influência de diversas características da qualidade da auditoria sobre a qualidade da informação contábil, esta mensurada pelo conservadorismo. Foram avaliadas informações contábeis produzidas pelas companhias abertas brasileiras no período de 2000 a 2011, utilizando o modelo desenvolvido por Ball e Shivakumar (2005). Entre os resultados encontrados, constatou-se que o conservadorismo da informação contábil é positivamente afetado pelo tamanho da firma de auditoria e negativamente afetado pelo tempo de prestação de serviço dos auditores, pela distância entre a data do parecer e a data de publicação das demonstrações contábeis. Observou-se, também, que variáveis como o comitê de auditoria, a prestação de serviços de não auditoria, a importância do cliente para a firma de auditoria e a especialização da auditoria não afetam o conservadorismo contábil.

Palavras-chave: auditoria; qualidade em auditoria; conservadorismo contábil; qualidade da informação contábil.

\author{
lana Izadora Souza \\ Lapa de Melo Paulo \\ Mestre em Ciências Contábeis \\ (UnB/UFPB/UFRN), Pesquisador da \\ Universidade Federal da Paraíba \\ (UFPB). Contato: Cidade Universitária \\ - Campus I, Castelo Branco, João \\ Pessoa, Paraíba, CEP: 58059-900. \\ E-mail: iana.melo@hotmail.com

\section{Paulo Roberto} \\ Nóbrega Cavalcante \\ Doutor em Ciências Contábeis (USP), \\ Professor da Universidade Federal \\ da Paraíba (UFPB). Contato: Cidade \\ Universitária - Campus I, Castelo \\ Branco, João Pessoa, Paraíba, CEP: \\ 58059-900. \\ E-mail: paulocavalcante@ccsa.ufpb.br
}

\section{Edilson Paulo}

Doutor em Ciências Contábeis (USP), Professor da Universidade Federal da Paraíba (UFPB). Contato: Cidade Universitária - Campus I, Castelo Branco, João Pessoa, Paraíba, CEP: 58059-900.

E-mail: e.paulo@uol.com.br

Os autores agradecem ao CNPq (Conselho Nacional de Desenvolvimento Científico e Tecnológico) por apoio e financiamento proporcionado ao projeto de pesquisa que originou este trabalho. 


\section{Introdução}

Apesar dos inúmeros trabalhos na literatura internacional, a qualidade das informações contábeis é um assunto que ainda carece de maiores estudos nos diversos ambientes econômicos (Dechow, Ge \& Schrand, 2010), inclusive no contexto brasileiro. Definir qualidade da informação contábil não tem sido uma tarefa simples. Um evento ou transação mensurado ou evidenciado de acordo com um determinado critério contábil pode ser considerado por um agente como uma informação de boa qualidade, enquanto outro agente econômico não lhe atribui a mesma qualidade.

A complexidade e a dinâmica das atividades empresariais dificultam uma conceituação concreta sobre qualidade da informação contábil. Diante dessa dificuldade, as pesquisas sobre o tema (Dechow \& Schrand, 2004; Burgstaher, Hail \& Leuz, 2006; Dechow et al., 2010) descrevem diversos atributos (ou características) da qualidade do conteúdo informacional da Contabilidade.

O conservadorismo é uma das principais características da qualidade das informações contábeis, de natureza subjetiva, e está inserido na maioria das estruturas conceituais de contabilidade. Diversos trabalhos analisaram conservadorismo nos diferentes ambientes econômicos e financeiros (Basu, 1997; Ball, Kothari \& Robin, 2000; Ball \& Shivakumar, 2005; Paulo, Antunes \& Formigoni, 2008; Dechow et al., 2010). De forma geral, os estudos consideram o conservadorismo como uma prática de reconhecimento assimétrico que privilegia o critério contábil com o menor ativo/receita ou maior passivo/despesa. Um maior reconhecimento oportuno das perdas (má notícia) é normalmente associado com o conservadorismo contábil (Basu, 1997).

O conservadorismo contábil pode ser influenciado pelas idiossincrasias de cada ambiente econômico. Um dos fatores seria o próprio conjunto de normas contábeis adotadas no país. Por exemplo, Ball et al. (2000) observaram que os resultados contábeis das firmas, em países com sistema jurídico commom law, são mais conservadores do que as empresas estabelecidas em países com sistema code law. Barth, Landsman e Lang (2008) evidenciam que as empresas que adotam as International Financial Reporting Standards (IFRS) apresentam perdas mais oportunamente do que aquelas que não as adotam.

Segundo Dechow et al. (2010), o reconhecimento da perda é mais oportuno quando os mecanismos de enforcement são mais fortes, como, por exemplo, sistema jurídico, auditoria, governança corporativa, etc. Entre esses mecanismos que levam os gestores a praticar o conservadorismo condicional está a auditoria externa. $\mathrm{O}$ trabalho dos auditores independentes é verificar se os relatórios contábeis produzidos pela entidade estão de acordo com as normas contábeis que a entidade está obrigada a cumprir.

Dechow et al. (2010) explicam que o impacto dos auditores sobre a qualidade das informações contábeis deriva do seu papel em mitigar a má representação intencional ou não intencional da realidade econômica e financeira da firma. Assim, as demonstrações contábeis examinadas por uma auditoria independente tendem a ter um melhor conteúdo informacional, conduzindo o usuário a tomar melhores decisões e, consequentemente, gerando maiores benefícios econômicos.

Muitos estudos têm se concentrando no efeito do tamanho da firma de auditoria (uma proxy para qualidade da auditoria) sobre as informações contábeis. Por exemplo, Francis e Wang (2008) observaram que o reconhecimento oportuno das perdas é maior nas empresas que são auditadas por uma firma de auditoria independente, classificada Big (Big-Four ou Big-Five).

Na literatura corrente, porém, existem poucas pesquisas que analisam a influência das outras características da auditoria sobre a qualidade das informações contábeis, tais como tempo de relacionamento entre o auditor e o cliente, a especialização da auditoria, o tipo de cliente, etc. Mesmo quando os estudos observam essas características, concentram-se sobre os aspectos de gerenciamento dos resultados contábeis.

Apesar da relevância, as pesquisas realizadas até o momento analisaram de forma segregada a relação entre as características da qualidade da auditoria independente e o nível de conservadorismo nas demonstrações contábeis, principalmente, no mercado de capitais brasileiro. Diante disso, pode-se levantar o seguinte problema de pesquisa: As características da qualidade da auditoria independente afetam o nível do conservadorismo dos relatórios contábeis reportados pelas empresas auditadas? O objetivo 
geral desta pesquisa é verificar se o nível do conservadorismo refletido nas demonstrações contábeis é influenciado pelas características da qualidade da auditoria independente no mercado de capitais brasileiro.

A literatura corrente sugere um conjunto de atributos para se mensurar a qualidade da auditoria e a qualidade da informação contábil. Mas as pesquisas, até então, têm se concentrado, basicamente, em avaliar a qualidade dos lucros e sua relação com o tamanho da empresa de auditoria independente. A investigação unicamente sobre o tamanho da firma de auditoria e accruals discricionários não contempla o amplo conjunto de variáveis que afetam a qualidade da auditoria e a qualidade das informações contábeis.

Portanto, esta pesquisa buscou analisar o conjunto de características da qualidade da auditoria, investigando fatores como tipo de cliente, período de relacionamento entre a auditoria e o cliente, tempo de emissão do relatório de auditoria, serviços de consultoria prestados pelas empresas de auditoria aos seus clientes auditados e importância do cliente. Essas características já foram estudadas em outros ambientes e, até mesmo, no contexto brasileiro, mas, praticamente, pouco se investigou sobre a relação entre as características da qualidade da auditoria e o conservadorismo contábil, um dos principais atributos da qualidade da informação contábil.

Na segunda seção deste trabalho, é apresentada uma revisão de literatura sobre o conservadorismo contábil e também sobre a relevância da auditoria e suas características. Na terceira seção, são apresentados os procedimentos metodológicos utilizados nesta pesquisa, seguido, na quarta seção, da apresentação e análise dos resultados empíricos. Por fim, descrevem-se as considerações finais, limitações e sugestões para futuras pesquisas.

\section{Referencial Teórico}

\subsection{A Informação Contábil e o Conservadorismo}

Considera-se que a informação contábil pode influenciar as decisões individuais de seus usuários, afetando a alocação dos recursos e o funcionamento dos mercados e, consequentemente, a eficiência da economia. Iudícibus $(2004$, p.25) afirma que "o objetivo básico da contabilidade [...] pode ser resumido no fornecimento de informações econômicas para vários usuários, de forma que propiciem decisões racionais".

Observando a Teoria da Agência, Lopes e Martins (2005, p.32-33) afirmam que o objetivo da firma "é a redução dos diversos custos associados aos contratos, sendo que seu funcionamento depende do equilíbrio contratual estabelecido, podendo ser prejudicado ou interrompido se alguma das partes estiver insatisfeita". Assim, o bom funcionamento dos contratos e, consequentemente, da firma, depende de informação de boa qualidade.

A Contabilidade busca apresentar informações úteis aos seus diversos usuários. Mas o crescente volume de transações e maior complexidade das atividades empresariais e as necessidades de informações dos administradores e dos demais usuários da Contabilidade tornam-se cada vez mais distintas.

Dentre os atributos da qualidade da informação contábil, o Conservadorismo é um dos mais discutido pelas pesquisas contábeis. Alguns estudos (Basu, 1997; Ball \& Shivakumar, 2005; Dechow et al., 2010) conceituam o conservadorismo como o reconhecimento enviesado das más notícias, mais rapidamente do que o das boas notícias. Para Basu (1997, p.3), o conservadorismo é o resultado que reflete as más notícias mais rapidamente do que as boas notícias, levando às "diferenças sistemáticas entre os períodos das más notícias e das boas notícias no timeliness e persistência dos resultados". Portanto, o conservadorismo implica decisões sobre o momento do reconhecimento oportuno dos ganhos e das perdas e, consequentemente, influencia a escolha contábil.

Entretanto, o International Accounting Standards Board (IASB) e o Financial Accounting Standards Board (FASB), por meio do Discussion Paper sobre a revisão da Estrutura Conceitual (IASB, 2013), estabelecem que conservadorismo não é uma qualidade desejável para as informações contábeis, pois esse atributo, provavelmente, gera um viés na posição e desempenho financeiro reportado pelas empresas. Assim, os preparadores devem tomar uma posição neutra quando lidar com a incerteza. 
Porém, Holthausen e Watts (2001), Watts (2003a, 2003b) e Ball e Shivakumar (2005) afirmam que o conservadorismo é importante no estabelecimento das relações contratuais entre a firma e seus credores, com intuito de assegurar garantias mínimas para o cumprimento das obrigações e na redução da probabilidade de que os recursos serão distribuídos inadequadamente para alguns agentes. Nessa linha, o conservadorismo aumenta a eficiência dos contratos por meio da redução do gerenciamento otimista dos resultados (para cima) da firma. Essa relação entre conservadorismo e contratos é mais evidente em ambientes onde a principal fonte de financiamento das firmas é mercado de crédito, em particular, em contratos de dívidas públicas (Ball et al., 2000; Nikolaev, 2010).

Entretanto, essa importância pode ser considerada relativa, pois, segundo Penman e Zhang (2002), o conservadorismo conduz para números contábeis de baixa qualidade, quando, por exemplo, cria reservas para mascarar a verdadeira performance da empresa.

Assim, a discussão sobre os benefícios do conservadorismo contábil ainda é uma questão inconclusiva. Esse questionamento sobre a utilidade, ou não, do conservadorismo é reconhecido, inclusive, no próprio Discussion Paper sobre a revisão da Estrutura Conceitual (IASB, 2013).

\subsection{Características da Qualidade da Auditoria Independente}

Segundo Sunder (1997), a principal contribuição da auditoria para a empresa é a verificação dos sistemas contábeis. A auditoria reduz a assimetria informacional por meio do exame e da validação das informações contábeis reportadas. Para Ruddock, Taylor e Taylor (2006, p.4), "os auditores podem adicionar valor às demonstrações financeiras pela redução da probabilidade da má representação deliberada da informação contábil".

Sunder (1997) adverte que a maioria das decisões dos auditores é baseada em suas crenças e julgamentos subjetivos sobre as informações contábeis reportadas e quanto aos aspectos econômicos e financeiros do cliente. Adicionalmente, pode-se considerar que julgamento também está relacionado à experiência do auditor e ao relacionamento com a empresa auditada. Mesmo diante da subjetividade, a perspectiva do usuário é de que a opinião da auditoria expressa plena confiança da realidade econômica e financeira da empresa auditada.

Segundo DeAngelo (1981, p.186), a qualidade da auditoria é composta pela probabilidade conjunta que o auditor possa detectar e reportar erros materiais no sistema contábil do cliente. A detecção de erros materiais está relacionada à competência técnica, enquanto que a divulgação desses erros remete à independência do auditor. A autora descreve que a competência do auditor é fortemente influenciada pela habilidade técnica do profissional, procedimentos e extensão dos exames realizados. O'Keefe, King e Gaver (1994, p. 44) descrevem a seguinte função da qualidade da auditoria:

$$
Q A=f(L ; K I S ; G C ; C S K ; C C)
$$

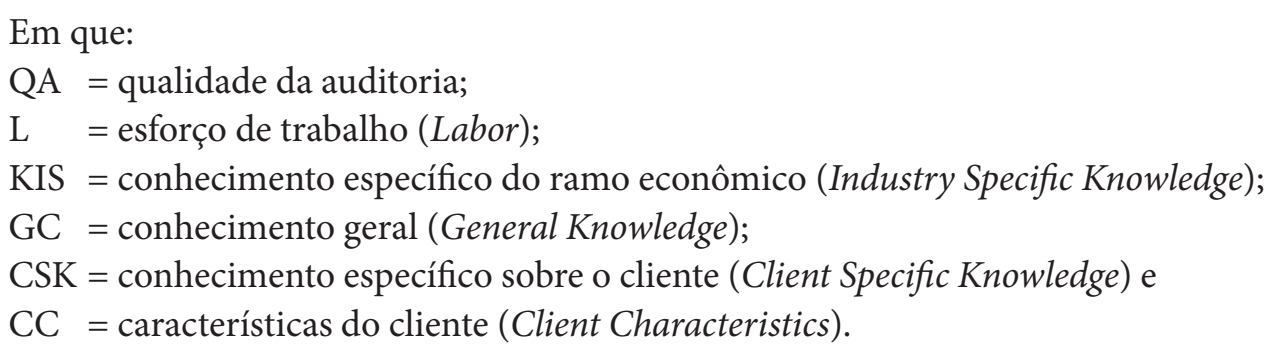

Portanto, a qualidade da auditoria é resultado do esforço de trabalho de maneira mais eficiente e alocação de recursos em conhecimentos específicos e gerais, sendo também afetado pelas características organizacionais e institucionais do cliente. 


\subsection{Relações entre as Características da Qualidade da Auditoria e a Qualidade das Informações Contábeis}

A qualidade das informações contábeis reportadas é influenciada pela qualidade da auditoria, pois ela restringe a manipulação dos números contábeis. Nessa linha de raciocínio, Becker et al. (1998) evidenciam que as firmas auditadas pelas maiores empresas de auditoria possuem menor nível de comportamento oportunístico. Piot (2005), com base em uma amostra de companhias francesas, apresenta resultados que corroboram os achados de Becker et al. (1998).

Assim, observa-se na literatura corrente que a qualidade da auditoria afeta positivamente a qualidade das informações contábeis. No que tange ao conservadorismo, espera-se que o conservadorismo contábil seja maior nas demonstrações contábeis das firmas em que se observem melhores serviços de auditoria.

Para facilitar a compreensão das relações entre as características da auditoria e a qualidade das informações contábeis, foi elaborada a Figura 1:

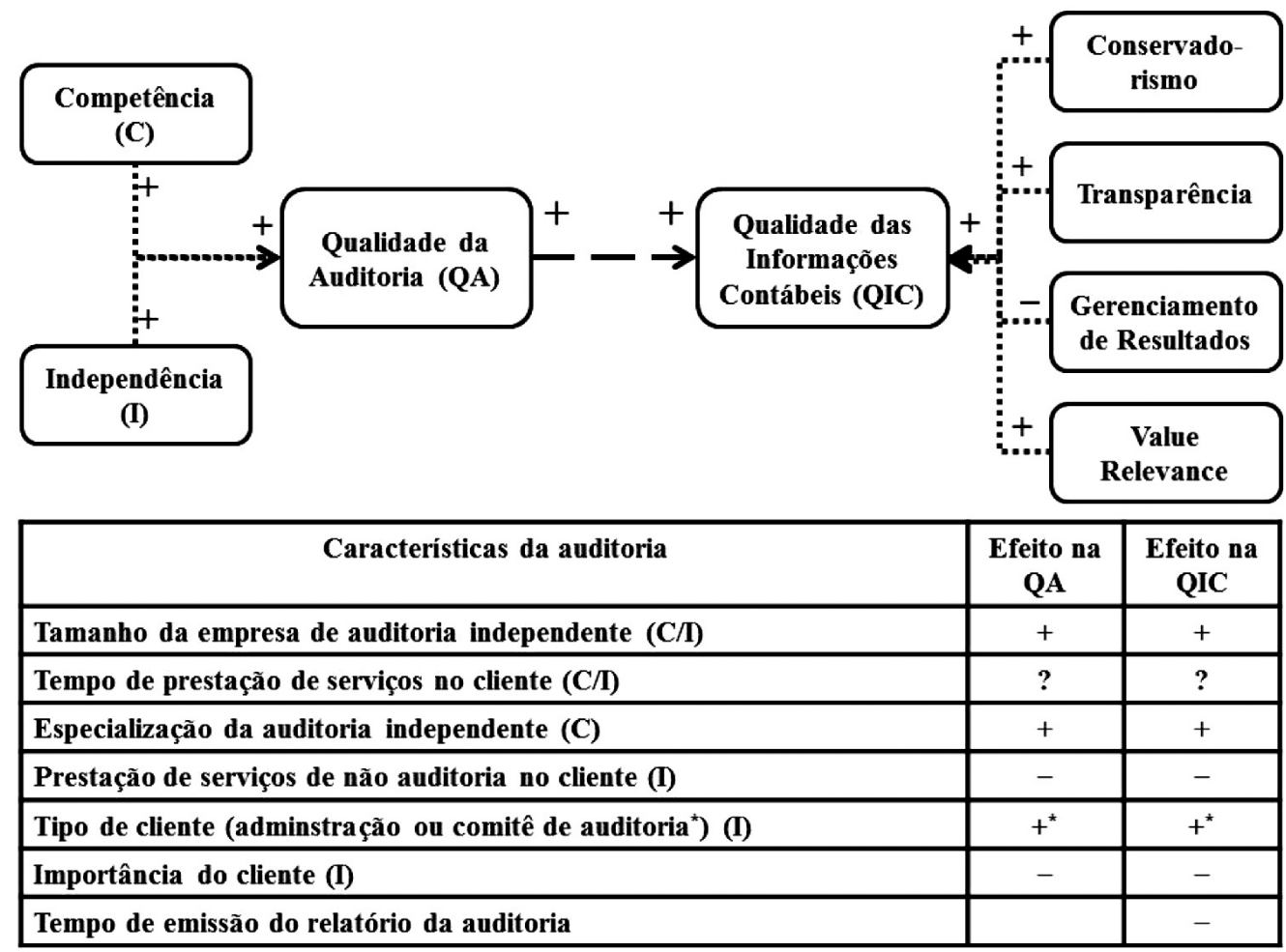

Fonte: Elaboração própria

Figura 1. Relações entre a Qualidade da Auditoria e a Qualidade das Informações Contábeis

Conforme descrito anteriormente, a qualidade da auditoria está relacionada, basicamente, a dois atributos: a competência e a independência dos profissionais da auditoria (DeAngelo, 1981). A literatura descreve que a qualidade dos serviços de auditoria é positivamente relacionada a esses dois atributos, ou seja, quanto maior a competência e/ou independência, maior a qualidade da auditoria. Essa relação pode ser visualizada na parte superior da Figura 1.

Da mesma forma, Dechow et al. (2010) relatam que os diversos estudos evidenciam um conjunto de atributos (constructos) para mensurar a qualidade das informações contábeis, mesmo com certo grau de dificuldade. Dentre os vários constructos da qualidade das informações contábeis, destacam-se conservadorismo, transparência, gerenciamento de resultados contábeis e value relevance. A maioria desses atributos tem uma relação direta com a qualidade das informações contábeis, como conservadorismo e transparência; para outras, porém, a relação é inversa, como o gerenciamento de resultados. Por exemplo, considera-se que números contábeis mais conservadores possuem maior qualidade do que os menos con- 
servadores, ou seja, relação positiva. Já no caso de gerenciamento de resultados, pela perspectiva oportunística, quanto menor a discricionariedade, maior a qualidade da informação contábil.

A despeito de muitos atributos poderem e, efetivamente, serem utilizados como indicativos da qualidade da informação contábil (Figura 1), neste trabalho optou-se pelo Conservadorismo, haja vista ser o atributo mais utilizado nas pesquisas que cuidam da qualidade da informação contábil.

Por fim, considera-se que uma melhor qualidade dos serviços de auditoria afeta, positivamente, a qualidade das informações contábeis. Consequentemente, a competência e a independência da auditoria afetam a qualidade dos números reportados pela Contabilidade.

Atributos que indicam a qualidade da auditoria: independência e competência, que podem ser mensurados com o uso de diversas características, sendo que entre tais características, algumas estão relacionadas tanto à competência, quanto à independência, enquanto outras características são associadas apenas à independência, que ora são analisadas nesta pesquisa:

\section{a) Tamanho da empresa de auditoria independente:}

Competência: considera-se que as maiores firmas de auditoria têm maior volume de recursos (financeiros e operacionais) e por isso podem prestar melhores serviços. Assim, quanto maior a empresa de auditoria, maior a qualidade da auditoria; logo, maior qualidade da informação contábil reportada por seu cliente (DeAngelo, 1981; O'Keefe et al, 1994; Braunbeck, 2010).

Independência: considera-se que as maiores firmas de auditoria têm maior independência financeira, com menor probabilidade, então, de aceitar práticas contábeis discricionárias ou agressivas. Assim, quanto maior a empresa de auditoria, maior a qualidade da auditoria; logo, maior qualidade da informação contábil reportada por seu cliente (DeAngelo, 1981, Fargher, Taylor \& Simon, 2001; Cupertino \& Martinez, 2008; Almeida \& Almeida, 2009).

\section{b) Tempo de prestação de serviços de auditoria no cliente:}

Competência: considera-se que um maior tempo de relacionamento entre uma firma de auditoria e seu cliente faz com que o auditor obtenha maior conhecimento sobre as atividades do seu cliente, conduzindo para uma melhor prestação de serviços (efeito aprendizagem). Assim, quanto mais tempo de relacionamento, maior a qualidade dos serviços de auditoria e maior qualidade da informação contábil reportada pelo cliente (Ghosh \& Moon, 2005, Jenkins \& Velury, 2008, Azevedo \& Costa, 2012). Independência: por outro lado, muitos autores consideram que um maior tempo de relacionamento faz com que o auditor tenha uma maior proximidade do seu cliente, o que afeta negativamente a qualidade dos serviços prestados. Assim, quanto mais tempo de relacionamento, menor a qualidade dos serviços de auditoria e menor qualidade da informação contábil reportada pelo cliente (DeFond \& Subramanyam, 1998; Li, 2010).

\section{c) Especialização da firma de auditoria:}

Competência: quanto mais especializada (maior conhecimento) for uma firma de auditoria em um determinado setor econômico, maior conhecimento sobre as atividades do seu cliente o auditor possuirá, logo prestará melhores serviços. Assim, quanto mais especializada em um ramo econômico, maior a qualidade dos serviços de auditoria e maior a qualidade da informação contábil reportada por seu cliente (O’Keefe et al., 1994; Sun \& Liu, 2011).

\section{d) Prestação de serviços de não auditoria na firma auditada:}

Independência: considera-se que a prestação de outros serviços de não auditoria faz com que o auditor se torne mais dependente do seu cliente, o que afeta negativamente a qualidade dos serviços prestados. Assim, quando se prestam serviços de não auditoria para a firma auditada, menor a qualidade dos serviços de auditoria e menor qualidade da informação contábil reportada pelo cliente (Chung \& Kallapur, 2003; Francis \& Ken, 2006; Ruddock et al., 2006). 
e) Tipo de Cliente da auditoria (administração ou comitê de auditoria):

Independência: a literatura considera que a empresa de auditoria pode ser contratada pela própria administração ou pelo comitê de auditoria. Observa-se que a independência do auditor é maior quando ele é contratado pelo comitê de auditoria, aumentando a qualidade dos serviços prestados. Assim, quando o auditor é contratado pelo referido comitê, maior a qualidade dos serviços de auditoria e maior a qualidade da informação contábil reportada pelo cliente (Myers, Myers \& Omer, 2003; Chen, Lin \& Lin, 2008; Koch, Weber \& Wüstemann, 2012).

\section{f) Importância do cliente:}

Independência: considera-se que alguns clientes são importantes para a firma de auditoria (consultoria), de tal forma que o auditor pode estar mais propenso a aceitar certas discricionariedades desses clientes, afetando negativamente a qualidade da auditoria. Assim, quanto mais importante for o cliente, menor a qualidade dos serviços de auditoria e da informação contábil reportada por seu cliente (DeAngelo, 1982; Chung \& Kallapur, 2003; Chin, Douthett \& Lisic, 2012).

\section{g) Tempo de emissão do relatório de auditoria:}

Algumas pesquisas apontam evidências de que o atraso na emissão do relatório de auditoria é um sinal de que existem problemas na contabilidade do cliente. Logo, sugere-se que, nesse caso, a empresa auditada possui menor qualidade de informação contábil. Essa característica não pode ser facilmente atribuída à competência e/ou à independência do auditor, pois, por exemplo, a demora na emissão do parecer pode ser relacionada, ou não, à capacidade de se detectarem falhas na contabilidade do cliente (Lobo \& Zhou, 2005; Krishnan \& Yang, 2009).

\section{Procedimentos Metodológicos}

\subsection{Tipo de Pesquisa}

O presente trabalho pode ser classificado como uma pesquisa descritiva, quanto aos seus objetivos, pois procura observar, registrar, analisar e correlacionar fatos e fenômenos sem manipulá-los. Quanto aos procedimentos, este trabalho pode ser classificado como uma pesquisa bibliográfica, pelo fato de procurar explicações sobre as características dos serviços de auditoria independente e o comportamento conservador dos relatórios contábeis a partir de referenciais teóricos que auxiliam o desenvolvimento das hipóteses de pesquisa. Por fim, esta pesquisa se utiliza a abordagem quantitativa, pois emprega métodos estatísticos para o tratamento dos dados (Beuren et al., 2006).

\subsection{Seleção e Composição da Amostra}

As informações necessárias à pesquisa foram obtidas nos bancos de dados da Comissão de Valores Mobiliários (CVM), da Reuters e das demonstrações contábeis publicadas pelas companhias abertas, no período de 2000 a 2011. A fim de se evitar viés na amostra e problemas de especificação na estimação dos modelos, foram excluídas deste trabalho: a) as companhias com dados ausentes necessários a este estudo e; b) as empresas que atuam na atividade financeira, administração de empresas e empreendimentos ou que tenham receitas operacionais exclusivamente oriundas de participações societárias, pois os procedimentos de mensuração contábil se diferenciam substancialmente das demais companhias e, provavelmente, não são capturados adequadamente pelos modelos analisados (Ball \& Shivakumar, 2005). 


\subsection{Hipóteses do Trabalho}

Para se alcançar o objetivo geral deste trabalho, foram levantadas algumas hipóteses de pesquisa.

A literatura contempla que o conservadorismo é afetado pelo porte (tamanho) da empresa de auditoria independente, sugerindo que firmas maiores de auditoria têm maior qualidade da auditoria, o que afeta positivamente a qualidade da informação contábil reportada por seu cliente (DeAngelo, 1981, DeFond \& Subramanyam, 1998; Fargher, Taylor \& Simon, 2001; Cupertino \& Martinez, 2008; Almeida \& Almeida, 2009). Assim, tem-se a primeira hipótese de pesquisa:

Hipótese 1: O nível de conservadorismo contido nas demonstrações contábeis é maior nas empresas auditadas pelas maiores firmas de auditoria independente do que pelas menores.

Diante da grande preocupação com a independência da auditoria, algumas firmas atribuem a contratação desses serviços ao comitê de auditoria (Myers, Myers \& Omer, 2003; Koch, Weber \& Wüstemann, 2012). Assim, levanta-se a Hipótese 2 desta pesquisa:

Hipótese 2: A existência de um comitê de auditoria responsável pela contratação dos auditores independentes afeta positivamente o nível de conservadorismo em suas demonstrações contábeis.

Em outro aspecto, depreende-se o fato de que um maior tempo de relacionamento entre o auditor e seu cliente pode afetar, negativamente, a qualidade da auditoria. Mas deve-se ressaltar que a literatura também contempla que a maior relação entre o auditor e o cliente auditado pode ser benéfica pelo fato de que esse profissional adquire ao longo do tempo maiores conhecimentos sobre o cliente e o seu ramo de atividade (De Fond \& Subramanyam, 1998; Ghosh \& Moon, 2005; Jenkins \& Velury, 2008; Li, 2010; Azevedo \& Costa, 2012). Entretanto, partindo da primeira suposição, tem-se a terceira hipótese de pesquisa:

Hipótese 3: O maior tempo de relacionamento entre o auditor e a firma auditada afeta negativamente o conservadorismo dos números contábeis.

As evidências apresentadas em alguns estudos demonstram o atraso na emissão do relatório de auditoria como um sinal de que existem problemas na contabilidade do cliente (Lobo \& Zhou, 2005; Krishnan \& Yang, 2009). Portanto, levanta-se a quarta hipótese deste trabalho:

Hipótese 4: O maior período entre a data das demonstrações contábeis e a data de emissão do relatório de auditoria independente é inversamente relacionado ao nível de conservadorismo encontrado nas demonstrações contábeis.

Como visto anteriormente, outros trabalhos sugerem que a prestação de outros serviços de não auditoria para a firma auditada prejudica a independência do auditor, ao passo que o auditor pode hesitar em não criticar o colega da área de consultoria da sua própria firma e a remuneração dos serviços de não auditoria pode estar vinculada ao desempenho favorável da firma, o que gera incentivos para comportamento oportunístico (Chung \& Kallapur, 2003; Francis \& Ken, 2006; Ruddock et al., 2006); logo, pode-se descrever a quinta hipótese de pesquisa:

Hipótese 5: A prestação de serviço de não auditoria afeta negativamente o conservadorismo dos números contábeis da empresa auditada. 
Outro fator relevante no ambiente das firmas de auditoria é a importância dos grandes clientes para seus negócios. Assim, considera-se que alguns clientes são muito importantes estrategicamente para os negócios da firma de auditoria, o que aumenta a probabilidade de menor conservadorismo desse cliente. Além do mais, empresas de auditoria com maior número de clientes apresentam menores incentivos para se comportarem oportunisticamente, o que gera uma percepção de maior qualidade de auditoria (DeAngelo, 1982; Gaver \& Paterson, 2001; Chung \& Kallapur, 2003; Chin, Douthett \& Lisic, 2012). Logo, a sexta hipótese é descrita como:

Hipótese 6: A importância do cliente para a firma de auditoria afeta negativamente o nível de conservadorismo nas demonstrações contábeis.

Por fim, uma maior especialização da firma de auditoria proporciona maiores conhecimentos sobre as atividades do seu cliente, afetando positivamente a qualidade dos serviços de auditoria e da informação contábil reportada pelo cliente. Com maior conhecimento, acredita-se que o auditor especializado tenha maior probabilidade de identificar alguma falha/erro material nas demonstrações contábeis (O'Keefe et al., 1994; Balsam, Krishnan \& Yang, 2003; Sun \& Liu, 2011). Logo, tem-se a sétima e última hipótese:

Hipótese 7: A maior especialização do auditor em um ramo de atividade econômica afeta positivamente o conservadorismo dos números contábeis reportados pela firma auditada.

\subsection{Definição do Modelo Empregado e Variáveis Operacionais}

Este trabalho utilizou o modelo desenvolvido por Ball e Shivakumar (2005) para avaliar o nível de conservadorismo contábil. Porém, com o intuito de capturar os efeitos da auditoria, foi incluída uma variável $\left(C_{i t}\right)$ para representar cada característica da auditoria no modelo original. Assim, o modelo empregado para se testar as hipóteses deste trabalho é descrito da seguinte forma:

$$
\begin{aligned}
& \Delta N I_{i t}=\alpha_{0}+\alpha_{1} D \Delta N I_{i t-1}+\alpha_{2} \Delta N I_{i t-1}+\alpha_{3} \Delta N I_{i t-1} \cdot D \Delta N I_{i t-1}+\alpha_{4} C_{i t} \\
& \quad+\alpha_{5} C_{i t} \cdot D \Delta N I_{i t-1}+\alpha_{6} C_{i t} \cdot \Delta N I_{i t-1}+\alpha_{7} C_{i t} \Delta N I_{i t-1} \cdot D \Delta N I_{i t-1}+\varepsilon_{i t}
\end{aligned}
$$

Em que:

$\Delta N I_{i t} \quad=$ variação no lucro líquido da empresa $i$ do ano $t-1$ para o ano $t$ ponderada pelo ativo total no início do ano $t$;

$\Delta N I_{i t-1}=$ variação no lucro líquido da empresa $i$ do ano $t-2$ para o ano $t-1$ ponderada pelo ativo total no início do ano $t-1$;

$D \Delta N I_{i t-1}=$ variável dummy para indicar se existe variação negativa no lucro líquido da empresa $i$ do ano $t-1$ para o ano $t$, assumindo valor 1 se $\Delta N I_{i t}<0$, e 0 nos demais casos;

$C_{i t} \quad=$ característica da qualidade de auditoria na empresa $i$ no ano $t$;

$\varepsilon_{i t} \quad=$ erro da regressão.

Segundo Ball e Shivakumar (2005), para que os resultados positivos se tornem um componente persistente do lucro contábil, o coeficiente $\alpha_{2}$ deve ser igual a zero $\left(\alpha_{2}=0\right)$, pois o reconhecimento dos ganhos é postergado até o momento em que os seus fluxos de caixa são realizados. Quando o coeficiente $\alpha_{2}$ é menor que zero $\left(\alpha_{2}<0\right)$ implica um reconhecimento oportuno, evidenciando que os ganhos são componentes transitórios nos resultados no período corrente e tendem a ser revertidos nos períodos subsequentes. Por outro lado, quando o coeficiente $\alpha_{3}$, é significativamente menor que zero $\left(\alpha_{3}<0\right)$; considera-se que existe reconhecimento oportuno das perdas. 
Para capturar se uma determinada característica da auditoria afeta o conservadorismo, deve-se analisar as variáveis multiplicativas entre a referida característica $\left(C_{i t}\right)$ e as variáveis do modelo original $\left(\Delta N I_{i t-1}\right.$ e $\left.D \Delta N I_{i t-1}\right)$, pois produz coeficientes de inclinação distintos, de forma tal que possibilita a verificação da mudança no nível de conservadorismo do modelo por meio da inclusão de uma variável qualitativa. Caso não fossem incluídas essas variáveis multiplicativas, a variável $C_{i t}$ refletiria somente o quanto a característica da auditoria afeta a variação do lucro líquido do período t-1 para o período $t\left(\Delta N I_{i t}\right)$ e, não, a variação no nível de conservadorismo.

Portanto, para se avaliar a característica analisada da auditoria, tem-se o pressuposto de que ela apresenta maior reconhecimento oportuno das perdas quando o coeficiente $\alpha_{7}$ é significativamente menor que $0\left(\alpha_{7}<0\right)$.

Todas as regressões serão estimadas por meio da abordagem pooling of independent cross sections. Foram criadas variáveis dummies para cada ano da amostra, exceto para os dados referentes ao ano de 2000, bem como para cada setor da atividade econômica da empresa, exceto para a categoria 'Outros', segundo classificação estabelecida pelo banco de dados Economática. O objetivo desse procedimento é minimizar os problemas de heteroscedasticidade. Adicionalmente, buscando melhores estimações dos parâmetros e, consequentemente, extrair inferências mais adequadas sobre os modelos analisados, foi utilizado o estimador de White para obter o erro-padrão robusto em relação à heteroscedasticidade (Wooldridge, 2002).

A literatura corrente não fornece fundamentações teóricas claras e consistentes que permitam identificar adequadamente os fatores endógenos e exógenos nas pesquisas sobre auditoria, inclusive no que se refere à simultaneidade das variáveis empregadas (Fargher et al., 2001, p. 409). Para cada uma das características da qualidade da auditoria, foram estabelecidas proxies, conforme a literatura corrente sobre o tema, apesar da complexidade em serem mensuradas. Essas proxies representam a variável 'característica da qualidade de auditoria' $\left(C_{i t}\right)$ na equação 2 descrita anteriormente.

\section{A. Tamanho da firma de auditoria independente $\left(\right.$ AUDTAM $\left._{i t}\right)$}

As pesquisas sobre auditoria (DeFond \& Subramanyam, 1998; Fargher et al., 2001; Cupertino \& Martinez, 2008; Lennox, Francis \& Wang, 2012) consideram como proxy o tamanho da firma de auditoria independente $\left(A U D T A M_{i t}\right)$, normalmente relacionada à reputação, se ela é, ou não, uma das denominadas Big Four (ou Big Five, se for o caso).

Nesse caso, se a empresa de auditoria foi realizada por uma das firmas Big (Four ou Five), a variável $T A M_{i t}$ assume valor 1, caso contrário 0. Este trabalho considerou, como firmas de auditoria pertencentes ao grupo das Big Four, as empresas PricewaterhouseCoopers, Deloitte Touche Tohmatsu, KPMG e Ernst \& Young; e inclui a Arthur Andersen, formando as Big Five. Adicionalmente, devido a algumas movimentações de participação no mercado de auditoria no Brasil, optou-se por se avaliarem as firmas de auditoria BDO Trevisan Auditores Independentes e Terco Grant Thornton, aqui denominadas de Middle.

\section{B. Tipo de cliente $\left(A U D C O N S_{i t}\right)$}

As pesquisas sobre auditoria, como Koch et al. (2012), consideram que a decisão das relações contratuais da auditoria independente com o comitê de auditoria pode contribuir para a independência da auditoria. Assim, caso a empresa auditada possua comitê de auditoria dentro da sua estrutura de governança, a variável $A U D C O N S_{i t}$ assume valor 1; em caso contrário, 0.

\section{Tempo de prestação de serviços de auditoria ao cliente (TENURE $\left.{ }_{i t}\right)$}

Consistentes com os trabalhos de Jenkins e Velury (2008), Li (2010) e Chin et al. (2012), utilizou-se como proxy, para o tempo de prestação de serviços ao cliente (TENURE $E_{i t}$, a quantidade de anos consecutivos em que a auditoria é realizada pela mesma empresa. 


\section{Tempo de emissão do relatório de auditoria $\left(D E L A Y_{i t}\right)$}

A variável $D E L A Y_{i t}$ representa o tempo de emissão do relatório de auditoria, sendo mensurada, conforme Ng e Tai (1994), por meio do número de dias entre o final do ano-competência e a data do parecer do auditor.

\section{E. Prestação de serviços de não auditoria ao cliente $\left(N A S_{i t}\right)$}

Para indicar se a empresa de auditoria prestou outros serviços ao cliente, além da auditoria, criou-se a variável $N A S_{i t}$, que assume valor 1 quando, naquele ano, ocorreram tais serviços; e valor 0 , em caso contrário (Chung \& Kallapur, 2003; Francis \& Ken, 2006). A informação sobre a prestação, ou não, de outros serviços de não auditoria ao cliente foi obtida através das Notas Explicativas e Relatório de Administração.

\section{F. Importância do cliente (IMPCLI $\left.{ }_{i t}\right)$}

Para indicar, se um determinado cliente, é importante na carteira de clientes da firma da auditoria independente, foi criada uma proxy $\left(I M P C L I_{i t}\right)$ que assume valor 1, se o logaritmo natural das receitas líquidas da empresa auditada representa mais de 15\% do somatório do logaritmo natural das receitas líquidas de todos os clientes da empresa de auditoria, caso contrário, ela assume valor 0 (Li, 2010; Sun \& Liu, 2011).

\section{G. Especialização da empresa de auditoria $\left(A U D E X P_{i t}\right)$}

Para indicar a expertise da auditoria independente, foi criada uma proxy $\left(A U D E X P_{i t}\right)$ que assume valor 1 , se a auditoria da empresa auditada tiver um portfolio de clientes do mesmo ramo econômico que representem mais de $15 \%$ da receita líquida das firmas da mesma atividade econômica; em caso contrário, 0 . Essa métrica é consistente com as utilizadas nos trabalhos de O'Keefe et al. (1994) e Sun e Liu (2011).

\section{H. Variáveis de controle}

Os estudos sobre auditoria frequentemente utilizam diversas variáveis para minimizar os efeitos da endogeneidade sobre os resultados de suas pesquisas (Lennox et al., 2012). Nesta pesquisa, utilizaram-se as seguintes variáveis:

a) Logaritmo do ativo total da firma auditada $\left(\operatorname{LnAT} T_{i t}\right)$ : Weber e Willenborg (2003), Chaney, Jeter e Shivakumar (2004) e Fortin e Pittman (2007);

b) Variável dummy para perdas contábeis da firma auditada (DLoss $\left.{ }_{i t}\right)$ : Chaney et al. (2004), Fortin e Pittman (2007) e Behn, Choi e Kang (2008);

c) Retorno sobre ativos da firma auditada $\left(R O A_{i t}\right)$ : Lennox et al. (2012);

d) Alavancagem da firma auditada (Alav $v_{i t}$ : Lennox et al. (2012);

e) Fluxo de caixa operacional $\left(F C O_{i t}\right.$ : Lennox et al. (2012);

A variável 'logaritmo do ativo total' tem como objetivo controlar o tamanho da empresa auditada; já as variáveis $D \operatorname{Loss}_{i t}$ e $R O A_{i t}$ buscam controlar os efeitos da lucratividade, enquanto que Alav $_{i t}$ e $F C O_{i t}$ controlam, respectivamente, o endividamento e o fluxo de caixa gerado da firma. Para todas as proxies de características da qualidade da auditoria foram coletadas os dados de cada ano ao longo do período da pesquisa. A variável $F C O_{i t}$ é calculada pelo fluxo de caixa operacional do período $t$ ponderada pelo ativo total do período $t-1$ da firma $i$. 


\section{Apresentação e Análise dos Resultados}

\subsection{Análise Descritiva das Variáveis}

Para atender ao objetivo desta pesquisa, foram avaliadas informações de 2.805 demonstrações contábeis, no período de 2000 a 2011, ocorrendo um crescimento no número de relatórios, de 177 em 2000 para 280 em 2011 (Tabela 1).

Tabela 1

Quantidade de demonstrações contábeis auditadas - firma de auditoria X ano

\begin{tabular}{|c|c|c|c|c|c|c|c|c|c|}
\hline Ano & DL & PWC & EY & KPMG & AA & BDO & TGT & OUT & Total \\
\hline 2000 & 17 & 29 & 20 & 9 & 43 & 14 & & 45 & 177 \\
\hline 2001 & 19 & 33 & 21 & 8 & 40 & 16 & & 45 & 182 \\
\hline 2002 & 46 & 47 & 19 & 10 & & 14 & & 52 & 188 \\
\hline 2003 & 48 & 37 & 23 & 11 & & 12 & 1 & 60 & 192 \\
\hline 2004 & 55 & 29 & 20 & 16 & & 14 & 1 & 64 & 199 \\
\hline 2005 & 64 & 28 & 22 & 19 & & 15 & 1 & 70 & 219 \\
\hline 2006 & 79 & 26 & 27 & 29 & & 17 & 8 & 69 & 255 \\
\hline 2007 & 56 & 35 & 33 & 44 & & 21 & 15 & 68 & 272 \\
\hline 2008 & 53 & 36 & 35 & 45 & & 27 & 18 & 60 & 274 \\
\hline 2009 & 51 & 36 & 45 & 46 & & 27 & 19 & 57 & 281 \\
\hline 2010 & 53 & 45 & 66 & 45 & & 28 & 1 & 48 & 286 \\
\hline 2011 & 52 & 47 & 70 & 59 & & 3 & 2 & 47 & 280 \\
\hline Total Geral & 593 & 428 & 401 & 341 & 83 & 208 & 66 & 685 & 2.805 \\
\hline $\begin{array}{l}\text { eegenda: } \mathrm{DL}=\mathrm{D} \\
\text { Thornton; OUT }\end{array}$ & ; PWC & $\begin{array}{l}E Y=E \\
\text { Auditor }\end{array}$ & Young & $\Lambda G=K P M$ & $=$ Arth & ersen; & DBO $\mathrm{Tr}$ & ; ; TGT = & o Grant \\
\hline
\end{tabular}

Na Tabela 1, observa-se, também, uma forte concentração de demonstrações contábeis das empresas auditadas pelo grupo das grandes firmas internacionais de auditoria, chamado de Big (Big Four ou Big Five, quando se inclui a Artur Andersen), na qual detiveram, em média, 65,8\% (1846/2805) dos relatórios analisados em todo o período desta pesquisa. Caso se considere as firmas BDO Trevisan e Terco Grant Thornton (Middle), essa participação passa, aproximadamente, para 75\% dos relatórios auditados no período de 2000 a 2011. Adicionalmente, verificou-se que essa grande concentração de empresas auditadas pelas Big tem crescido ao longo do tempo, sendo que em 2000, elas tinham $66,7 \%$ do mercado, chegando em 2011, a um percentual de participação em torno de $81,4 \%$.

$\mathrm{Na}$ Tabela 2 verifica-se que, durante o período de análise desta pesquisa, em média, 90\% dos relatórios do auditor independente sobre as demonstrações contábeis, ou parecer do auditor independente, como era denominado até a revogação da NBC T 11, foi opinião não modificada, anteriormente conhecida como parecer sem ressalva. Observa-se que, ao longo dos anos, o número de opinião não modificada tem crescido em termos percentuais. Esse número pode sugerir que as companhias abertas auditadas ao longo do tempo tenham melhorado os procedimentos de controle interno e de contabilidade, em resposta a diversos escândalos financeiros ocorridos nos anos de 2001 e 2002. 
Porém, cabe ressaltar, que esses dados também podem sugerir uma redução na atenção dada sobre os números das companhias abertas por parte das firmas de auditoria, após uma resposta temporária aos referidos escândalos.

Tabela 2

Percentual de demonstrações contábeis auditadas - firma de auditoria $X$ ano

\begin{tabular}{|c|c|c|c|c|c|c|c|c|c|c|}
\hline \multirow{4}{*}{ Ano } & \multicolumn{10}{|c|}{ Tipo de Relatório de Auditoria } \\
\hline & \multirow{2}{*}{\multicolumn{2}{|c|}{$\begin{array}{c}\text { Opinião não } \\
\text { Modificada } \\
\text { (Sem Ressalva) }\end{array}$}} & \multicolumn{6}{|c|}{ Opinião não Modificada } & \multirow{2}{*}{\multicolumn{2}{|c|}{ Total }} \\
\hline & & & \multicolumn{2}{|c|}{ Com Ressalva } & \multicolumn{2}{|c|}{ Negativa de Opinião } & \multicolumn{2}{|c|}{ Adversa } & & \\
\hline & Qtde. & $\%$ & Qtde. & $\%$ & Qtde. & $\%$ & Qtde. & $\%$ & Qtde. & $\%$ \\
\hline 2000 & 151 & 85,3 & 24 & 13,6 & 1 & 0,6 & 1 & 0,6 & 177 & 100 \\
\hline 2001 & 153 & 84,1 & 27 & 14,8 & 1 & 0,5 & 1 & 0,5 & 182 & 100 \\
\hline 2002 & 161 & 85,6 & 25 & 13,3 & 1 & 0,5 & 1 & 0,5 & 188 & 100 \\
\hline 2003 & 160 & 83,3 & 30 & 15,6 & 1 & 0,5 & 1 & 0,5 & 192 & 100 \\
\hline 2004 & 167 & 83,9 & 31 & 15,6 & 1 & 0,5 & & 0,0 & 199 & 100 \\
\hline 2005 & 196 & 89,5 & 23 & 10,5 & & 0,0 & & 0,0 & 219 & 100 \\
\hline 2006 & 236 & 92,5 & 17 & 6,7 & 2 & 0,8 & & 0,0 & 255 & 100 \\
\hline 2007 & 257 & 94,5 & 14 & 5,1 & 1 & 0,4 & & 0,0 & 272 & 100 \\
\hline 2008 & 252 & 92,0 & 20 & 7,3 & 2 & 0,7 & & 0,0 & 274 & 100 \\
\hline 2009 & 266 & 94,7 & 12 & 4,3 & 3 & 1,1 & & 0,0 & 281 & 100 \\
\hline 2010 & 264 & 92,3 & 19 & 6,6 & 3 & 1,0 & & 0,0 & 286 & 100 \\
\hline 2011 & 261 & 93,2 & 16 & 5,7 & 3 & 1,1 & & 0,0 & 280 & 100 \\
\hline Total & 2.524 & 90,0 & 258 & 9,2 & 19 & 0,7 & 4 & 0,1 & 2.805 & 100 \\
\hline
\end{tabular}

A Tabela 3 demonstra um crescimento na implantação do Comitê de Auditoria por parte das empresas listadas na BM\&FBovespa, sendo que, provavelmente, elas foram motivadas pela busca da melhoria nos seus sistemas de Governança Corporativa. Por outro lado, verifica-se que, gradativamente, houve uma redução na quantidade de prestação de outros serviços por parte das firmas de auditoria (NAS) aos seus clientes auditados. Esse fato também pode ser explicado pela busca na melhoria dos sistemas de Governança Corporativa, seja voluntariamente ou de forma coerciva, por meio de regulação de mercado (como por exemplo, a Lei Sarbanes-Oxley nos Estados Unidos da América). A simples divulgação de que a firma de auditoria obtém outras rendas diferentes dos serviços de auditoria, pode levar o leitor das demonstrações contábeis, considerar que tal relacionamento pode ter prejudicado a qualidade dos serviços de auditoria e, consequentemente, a qualidade das informações reportadas pela empresa.

Cabe ressaltar que, só a partir de 2002, verificou a informações sobre serviços de não auditoria por parte das companhias abertas brasileiras. 
Tabela 3

Evolução do Comitê de Auditoria e Serviços de Não Auditoria (NAS)

\begin{tabular}{|c|c|c|c|c|c|c|c|c|c|c|c|c|}
\hline \multirow{3}{*}{ Ano } & \multicolumn{6}{|c|}{ Comitê de Auditoria } & \multicolumn{6}{|c|}{ Serviços de não Auditoria (NAS) } \\
\hline & \multicolumn{2}{|c|}{ Não } & \multicolumn{2}{|c|}{ Sim } & \multicolumn{2}{|c|}{ Total } & \multicolumn{2}{|c|}{ Não } & \multicolumn{2}{|c|}{ Sim } & \multicolumn{2}{|c|}{ Total } \\
\hline & Qtde. & $\%$ & Qtde. & $\%$ & Qtde. & $\%$ & Qtde. & $\%$ & Qtde. & $\%$ & Qtde. & $\%$ \\
\hline 2000 & 175 & 98,9 & 2 & 1,1 & 177 & 100,0 & & & & & & \\
\hline 2001 & 179 & 98,4 & 3 & 1,6 & 182 & 100,0 & & & & & & \\
\hline 2002 & 179 & 95,2 & 9 & 4,8 & 188 & 100,0 & 160 & 85,1 & 28 & 14,9 & 188 & 100,0 \\
\hline 2003 & 180 & 93,8 & 12 & 6,3 & 192 & 100,0 & 169 & 88,0 & 23 & 12,0 & 192 & 100,0 \\
\hline 2004 & 180 & 90,5 & 19 & 9,5 & 199 & 100,0 & 183 & 92,0 & 16 & 8,0 & 199 & 100,0 \\
\hline 2005 & 190 & 86,8 & 29 & 13,2 & 219 & 100,0 & 200 & 91,3 & 19 & 8,7 & 219 & 100,0 \\
\hline 2006 & 218 & 85,5 & 37 & 14,5 & 255 & 100,0 & 235 & 92,2 & 20 & 7,8 & 255 & 100,0 \\
\hline 2007 & 220 & 80,9 & 52 & 19,1 & 272 & 100,0 & 251 & 92,3 & 21 & 7,7 & 272 & 100,0 \\
\hline 2008 & 216 & 78,8 & 58 & 21,2 & 274 & 100,0 & 248 & 90,5 & 26 & 9,5 & 274 & 100,0 \\
\hline 2009 & 220 & 78,3 & 61 & 21,7 & 281 & 100,0 & 253 & 90,0 & 28 & 10,0 & 281 & 100,0 \\
\hline 2010 & 221 & 77,3 & 65 & 22,7 & 286 & 100,0 & 245 & 85,7 & 41 & 14,3 & 286 & 100,0 \\
\hline 2011 & 207 & 73,9 & 73 & 26,1 & 280 & 100,0 & 234 & 83,6 & 46 & 16,4 & 280 & 100,0 \\
\hline Total & 2.385 & 85,0 & 420 & 15,0 & 2805 & 100,0 & 2877 & 91,5 & 268 & 8,5 & 3145 & 100,0 \\
\hline
\end{tabular}

Fonte: Própria

Na Tabela 4 são apresentadas as estatísticas descritivas das variáveis contínuas utilizadas neste estudo; observa-se que nenhuma das variáveis tem distribuição normal, conforme teste de Jarque-Bera. Apesar de que, em média, o lucro do período ser positivo, a amostra apresenta uma variação média negativa entre no lucro, como um retorno sobre ativo (ROA) também negativo. Por outro lado, as empresas têm apresentado um fluxo de caixa operacional médio positivo no período.

Tabela 4

Estatísticas descritivas das variáveis continuas

\begin{tabular}{lrrrrrr} 
& \multicolumn{1}{c}{$\boldsymbol{N I}_{i t}$} & \multicolumn{1}{c}{$\boldsymbol{\Delta} \mathbf{N I}_{\boldsymbol{i t}}$} & $\mathbf{L n A T}_{i t}$ & $\boldsymbol{R O A}_{i t}$ & Alav $_{\boldsymbol{i t}}$ & $\boldsymbol{F C O}_{\boldsymbol{i t}}$ \\
\hline Média & 0,0092 & $-0,4973$ & 14,2929 & $-0,5315$ & 0,3250 & 0,0676 \\
\hline Mediana & 0,0458 & 0,0100 & 14,3528 & 0,0550 & 0,2856 & 0,0815 \\
\hline Desvio-Padrão & 0,6339 & 20,1161 & 1,9003 & 21,6813 & 0,6218 & 0,1656 \\
\hline Jarque-Bera & 74639772 & 139000000 & 89 & 139000000 & 16011858 & 67879 \\
& $(0,000)$ & $(0,000)$ & $(0,000)$ & $(0,000)$ & $(0,000)$ & $(0,000)$ \\
\hline Observações & 1.502 & 1.502 & 1.502 & 1.502 & 1.502 & 1.502 \\
\hline
\end{tabular}

Em que: $N I_{i t}=$ lucro líquido da empresa $i$ do ano $t$ ponderada pelo ativo total no início do ano $t ; \Delta N I_{i t}=$ variação no lucro líquido da empresa $i$ do ano $t$-1 para o ano $t$ ponderada pelo ativo total no início do ano $t ; \Delta N I_{i t-1}=$ variação no lucro líquido da empresa $i$ do ano $t$-2 para o ano $t-1$ ponderada pelo ativo total no início do ano $t-1 ; D \Delta N l_{i t-1}=$ variável dummy para indicar se existe variação negativa no lucro líquido da empresa $i$ do ano $t-1$ para o ano $t$, assumindo valor 1 se $\Delta N I_{i t}<0$, e 0 nos demais casos; $C_{i t}=$ característica da qualidade de auditoria na empresa $i$ no ano $t ; L_{n} A T_{i t}=$ logaritmo do ativo total da firma auditada; $D L o s s_{i t}=$ variável dummy para indicar se o lucro líquido da empresa $i$ no ano $t$ foi negativo, assumindo valor 1 se $N I_{i t}<0$, e 0 nos demais casos; $R O A_{i t}=$ retorno sobre ativos da firma auditada da empresa $i$ no ano $t ; A^{\prime a v} v_{i t}=$ alavancagem da firma da $i$ no ano $t ;\left(F C O_{i t}\right)=$ Fluxo de caixa operacional da empresa $i$ no ano $t$ ponderada pelo ativo total no início do ano $t$

Fonte: Própria 


\subsection{Análise das Hipóteses de Pesquisa}

Para análise do efeito de cada característica da auditoria, inicialmente, estimaram-se os parâmetros para o modelo original descrito por Ball e Shivakumar (2005), denominada neste trabalho como Original. Em seguida, estimaram-se os parâmetros da equação, na qual foi incluída a variável dummy para indicar cada característica para empresa-ano, com o intuito de testar as hipóteses desta pesquisa.

A primeira hipótese busca analisar se o nível de conservadorismo nas demonstrações contábeis é afetado pelo tamanho da firma de auditoria.

Inicialmente, com base nos dados apresentados na coluna Original, verifica-se que os resultados apresentados na Tabela 5 permite indicar que o coeficiente $\alpha_{2}$ é, estatisticamente, igual a zero ( $p$-value $>0,05$ ), confirmando a expectativa de que os resultados positivos não são revertidos nos períodos subsequentes, pois tornaram-se componente persistente do resultado contábil. Diferentemente, para o coeficiente $\alpha_{3,}$ foi encontrado valor negativo e relevante, indicando que as variações negativas no lucro contábil são mais transitórias; esse fato sugere que as perdas são reconhecidas mais rapidamente do que os ganhos econômicos. Além disso, observa-se que a soma dos coeficientes $\alpha_{2}$ e $\alpha_{3}(0,5416-0,9712=-0,4296)$ é, segundo teste Wald, significativamente menor que zero $\left(\alpha_{2}+\alpha_{3}<0\right)$, o que corrobora a hipótese de reconhecimento oportuno das perdas. Essas evidências sugerem que as companhias abertas brasileiras apresentam diferenças significativas no reconhecimento oportuno das perdas contábeis, ou seja, elas possuem um comportamento conservador.

Tabela 5

Relação do Conservadorismo com o Tamanho da Firma de Auditoria e o Tipo de Cliente

\begin{tabular}{|c|c|c|c|c|c|c|c|c|}
\hline & \multicolumn{2}{|c|}{ Original } & \multicolumn{2}{|c|}{$\begin{array}{c}\text { Tamanho da firma } \\
\text { de auditoria } \\
\text { (BIG) }\end{array}$} & \multicolumn{2}{|c|}{$\begin{array}{c}\text { Tamanho da firma } \\
\text { de auditoria } \\
\text { (BIG + Middle) }\end{array}$} & \multicolumn{2}{|c|}{$\begin{array}{l}\text { Tipo de cliente } \\
\text { (AUDCOM) }\end{array}$} \\
\hline & coeficiente & p-value & coeficiente & p-value & coeficiente & p-value & coeficiente & p-value \\
\hline Interceptor & $-0,018$ & 0,928 & 0,150 & 0,387 & 0,128 & 0,461 & $-0,031$ & 0,870 \\
\hline$D \Delta N I_{i t-1}$ & 0,064 & 0,020 & 0,036 & 0,350 & 0,063 & 0,154 & 0,074 & 0,010 \\
\hline$\Delta N I_{i t-1}$ & 0,541 & 0,127 & $-0,184$ & 0,027 & $-0,127$ & 0,143 & 0,544 & 0,000 \\
\hline$\Delta N I_{i t-1} * D \Delta N I_{i t-1}$ & $-0,971$ & 0,041 & $-0,188$ & 0,151 & $-0,083$ & 0,557 & $-0,969$ & 0,000 \\
\hline$C_{i t}$ & & & 0,003 & 0,922 & 0,009 & 0,793 & 0,092 & 0,075 \\
\hline$C_{i t}{ }^{*} D \Delta N I_{i t-1}$ & & & 0,013 & 0,781 & $-0,014$ & 0,792 & $-0,101$ & 0,198 \\
\hline$C_{i t}{ }^{*} \Delta N I_{i t-1}$ & & & 0,762 & 0,000 & 0,700 & 0,000 & $-1,089$ & 0,063 \\
\hline$C_{i t}{ }^{*} \Delta N I_{i t-1 *} D \Delta N I_{i t-1}$ & & & $-0,506$ & 0,000 & $-0,747$ & 0,000 & 1,071 & 0,229 \\
\hline $\operatorname{LnAT} T_{i t-1}$ & $-0,007$ & 0,650 & $-0,019$ & 0,008 & $-0,019$ & 0,011 & $-0,008$ & 0,261 \\
\hline$D \operatorname{Loss}_{i t-1}$ & $-0,109$ & 0,000 & $-0,082$ & 0,004 & $-0,086$ & 0,003 & $-0,108$ & 0,000 \\
\hline$R O A_{i t-1}$ & 0,030 & 0,012 & 0,008 & 0,144 & 0,018 & 0,000 & 0,030 & 0,000 \\
\hline$A L A V_{i t-1}$ & 0,003 & 0,748 & 0,000 & 0,654 & 0,004 & 0,055 & 0,003 & 0,053 \\
\hline $\mathrm{FCO}_{i t-1}$ & 0,271 & 0,058 & 0,260 & 0,000 & 0,252 & 0,000 & 0,281 & 0,000 \\
\hline$R^{2}$ & 0,291 & & 0,321 & & 0,316 & & 0,295 & \\
\hline$R^{2}$ ajustado & 0,276 & & 0,305 & & 0,300 & & 0,278 & \\
\hline F-statistic & 20,087 & 0,000 & 20,989 & 0,000 & 20,514 & 0,000 & 17,786 & 0,000 \\
\hline White Test & 23,849 & 0,000 & 38,133 & 0,000 & 32,106 & 0,000 & 20,722 & 0,000 \\
\hline Serial Correlation LM & 83,722 & 0,000 & 127,168 & 0,000 & 124,300 & 0,000 & 80,358 & 0,000 \\
\hline Jarque-Bera & $1,4 \mathrm{E}+7$ & 0,000 & $1,4 \mathrm{E}+7$ & 0,000 & $1,4 \mathrm{E}+7$ & 0,000 & $1,1 \mathrm{E}+7$ & 0,000 \\
\hline Observações & 1.998 & & 1.998 & & 1.998 & & 1.871 & \\
\hline \multicolumn{9}{|c|}{ 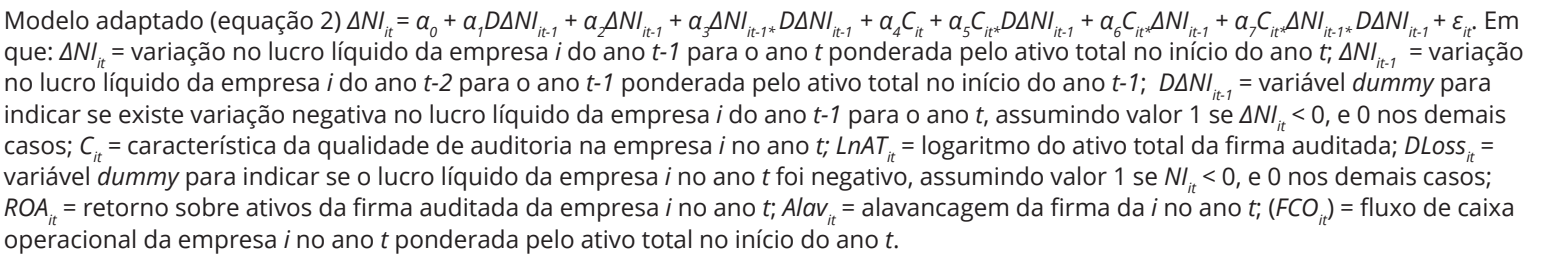 } \\
\hline
\end{tabular}


Analisando-se os parâmetros do modelo para todas as proxies de tamanho da firma de auditoria (Big 4, Big 5 e Big 5 + Middle), verificaram-se que os coeficientes $\alpha_{2}$ e $\alpha_{3}$ não são significativamente diferente de zero, entretanto, as mesmas variáveis multiplicadas pela variável AUDTAM ${ }_{i t}$ são relevantes para o modelo ampliado (equação 2).

Observa-se que a soma dos coeficientes $\alpha_{2}, \alpha_{3}, \alpha_{6}$ e $\alpha_{7}$ é menor que zero, indicando que as demonstrações contábeis das companhias abertas têm reconhecimento oportuno das perdas. Avaliando-se o comportamento conservador dos números contábeis diante do tamanho da firma de auditoria, o coeficiente $\alpha_{7}$ é negativo e significante (para todas as amostras), indicando que as variações negativas dos resultados são menos persistentes do que os ganhos. Essas evidências sugerem que as companhias abertas brasileiras apresentam maior nível de conservadorismo contábil quando são auditadas por uma das grandes firmas de auditoria.

Assim, os resultados apresentados corroboram a primeira hipótese de pesquisa, na qual coloca que o nível de conservadorismo contido nas demonstrações contábeis é maior nas empresas auditadas pelas maiores firmas de auditoria independente do que pelas menores firmas de auditoria.

A literatura sobre o tema descreve que o tipo de cliente afeta a qualidade da auditoria. O tipo de cliente refere-se ao gestor ou órgão administrativo da firma que tem a responsabilidade pela contratação da auditoria independente. Com a implantação do Comitê de Auditoria por parte das empresas, a atribuição da contratação passou a ser desse órgão administrativo, buscando ampliar a independência da firma de auditoria e, consequentemente, melhorar a qualidade dos seus serviços.

Observa-se na última coluna da Tabela 5 que os coeficientes $\alpha_{4}, \alpha_{5}, \alpha_{6}$, e $\alpha_{7}$, que representam a variável $A U D C O M_{i t}$ (comitê de auditoria) e as interações dessa variável com as demais do modelo original, não são significativamente diferente de zero ( $p$-value $>0,05$ ). A soma dos coeficientes $\alpha_{2}, \alpha_{3}, \alpha_{6}$ e $\alpha_{7}$ é igual a $-0,4424$, indicando reconhecimento oportuno das perdas, pois é menor que zero. Entretanto, essa soma não é significativamente diferente da soma dos coeficientes $\alpha_{2}$ e $\alpha_{3}(-0,4248)$, corroborando a evidência anterior. Esses resultados sugerem que a criação do Comitê de Auditoria não afeta significativamente o comportamento conservador dos números contábeis das empresas analisadas. Portanto, não foi confirmada a hipótese de que a existência de um comitê de auditoria responsável pela contratação dos auditores independentes afeta positivamente o nível de conservadorismo em suas demonstrações contábeis.

Outra hipótese levantada na pesquisa é que o tempo de relacionamento reduz o conservadorismo contábil, pois prejudica a qualidade da auditoria e da informação contábil. 
Tabela 6

\section{Relação do Conservadorismo com o Tempo de Relacionamento (Tenure), Rodízio e Tempo de Emissão} (Audit Delay)

\begin{tabular}{|c|c|c|c|c|c|c|c|c|}
\hline & \multicolumn{2}{|c|}{ Original } & \multicolumn{2}{|c|}{$\begin{array}{c}\text { Tempo de prestação } \\
\text { de serviços de } \\
\text { auditoria (TENURE) }\end{array}$} & \multicolumn{2}{|c|}{ Rodízio } & \multicolumn{2}{|c|}{$\begin{array}{l}\text { Tempo de emissão } \\
\text { do relatório (DELAY) }\end{array}$} \\
\hline & coeficiente & $p$-value & coeficiente & $p$-value & coeficiente & $p$-value & coeficiente & p-value \\
\hline Interceptor & $-0,018$ & 0,928 & $-0,232$ & 0,328 & $-0,114$ & 0,528 & 0,286 & 0,203 \\
\hline$D \Delta N I_{i t-1}$ & 0,064 & 0,021 & 0,200 & 0,030 & 0,032 & 0,088 & $-0,116$ & 0,120 \\
\hline$\Delta N I_{i t-1}$ & 0,542 & 0,128 & 2,012 & 0,040 & 0,769 & 0,000 & $-1,957$ & 0,025 \\
\hline$\Delta N I_{i t-1} * D \Delta N I_{i t-1}$ & $-0,971$ & 0,041 & $-2,667$ & 0,007 & $-0,570$ & 0,000 & 2,168 & 0,048 \\
\hline$C_{i t}$ & & & 0,029 & 0,066 & 0,008 & 0,601 & $-0,003$ & 0,010 \\
\hline$C_{i t}{ }^{*} D \Delta N I_{i t-1}$ & & & $-0,023$ & 0,184 & $-0,024$ & 0,390 & 0,002 & 0,042 \\
\hline$C_{i t}^{*} \Delta N I_{i t-1}$ & & & $-0,323$ & 0,099 & 0,122 & 0,025 & 0,021 & 0,005 \\
\hline$C_{i t}{ }^{*} \Delta N I_{i t-1} * D \Delta N I_{i t-1}$ & & & 0,467 & 0,044 & $-0,392$ & 0,029 & $-0,026$ & 0,004 \\
\hline$L n A T_{i t-1}$ & $-0,007$ & 0,651 & $-0,003$ & 0,841 & $-0,006$ & 0,675 & $-0,018$ & 0,256 \\
\hline DLoss ${ }_{i t-1}$ & $-0,109$ & 0,000 & $-0,132$ & 0,000 & $-0,044$ & 0,033 & $-0,074$ & 0,008 \\
\hline$R O A_{i t-1}$ & 0,031 & 0,013 & 0,015 & 0,348 & $-0,164$ & 0,000 & $-0,001$ & 0,973 \\
\hline$A L A V_{i t-1}$ & 0,003 & 0,748 & 0,009 & 0,334 & $-0,022$ & 0,003 & 0,004 & 0,645 \\
\hline $\mathrm{FCO}_{i t-1}$ & 0,272 & 0,058 & 0,327 & 0,039 & 0,274 & 0,053 & 0,283 & 0,061 \\
\hline$R^{2}$ & 0,291 & & 0,369 & & 0,593 & & 0,420 & \\
\hline$R^{2}$ ajustado & 0,277 & & 0,353 & & 0,584 & & 0,406 & \\
\hline F-statistic & 20,088 & 0,000 & 24,294 & 0,000 & 65,194 & 0,000 & 30,020 & 0,000 \\
\hline White Test & 23,849 & 0,000 & 12,926 & 0,000 & 8,181 & 0,000 & 7,426 & 0,000 \\
\hline Serial Correlation LM & 83,722 & 0,000 & 63,931 & 0,000 & 17,869 & 0,000 & 1597,80 & 0,000 \\
\hline Jarque-Bera & $1,4 \mathrm{E}+7$ & 0,000 & $8 \mathrm{E}+06$ & 0,000 & $5 E+07$ & 0,000 & $1,5 \mathrm{E}+8$ & 0,000 \\
\hline Observações & 1.998 & & 1.872 & & 1.872 & & 1.866 & \\
\hline \multicolumn{9}{|c|}{ 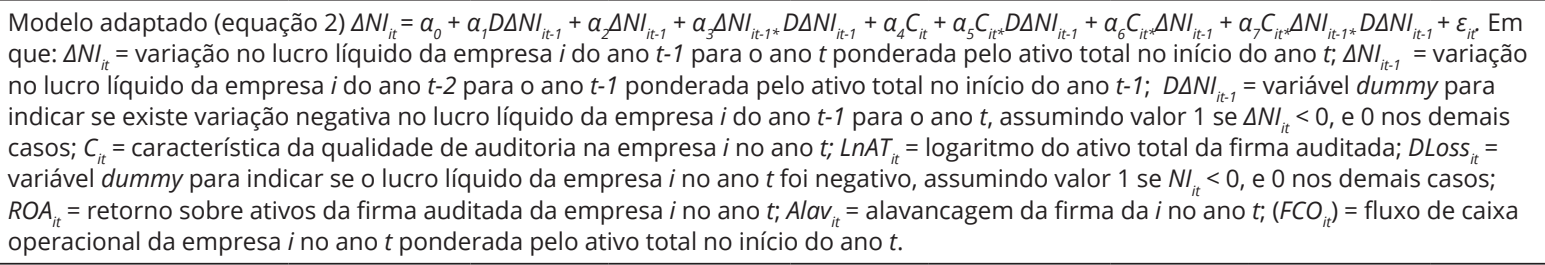 } \\
\hline
\end{tabular}

Observa-se na coluna Tenure da Tabela 6 que o coeficiente $\alpha_{7}$ é positivo e estatisticamente significante para o modelo. Além disso, o coeficiente $\alpha_{2}$ tornou-se estatisticamente significante, indicando reconhecimento oportuno de ganhos. Esses resultados são confirmados pela soma dos coeficientes $\alpha_{2}, \alpha_{3}, \alpha_{6} \mathrm{e}$ $\alpha_{7}$, cujo somatório desses parâmetros é igual a -0,5103, maior do que os coeficientes $\alpha_{2}$ e $\alpha_{3}(-0,6545)$. Tais evidências sugerem que o maior tempo de prestação de serviços de auditoria afeta negativamente a qualidade dos serviços de auditoria, reduzindo o nível de conservadorismo dos números contábeis.

Com base nesses resultados, optou-se por verificar, adicionalmente, se, no ano anterior à mudança da firma de auditoria houve um aumento no nível de conservadorismo nas demonstrações reportadas pelas companhias abertas brasileiras. Para tanto, criou-se uma variável dummy para indicar o ano em que ocorreu a mudança da firma de auditoria, assumindo valor 1, e valor 0 para os demais anos. Os parâmetros para essa análise também estão apresentados na coluna Rodizio da Tabela 6.

As estatísticas apresentadas indicam que os coeficientes $\alpha_{2}, \alpha_{3}, \alpha_{6}$ e $\alpha_{7}$ são estatisticamente significativos, somando o valor de $-0,0712$. O coeficiente $\alpha_{7}(-0,3924)$ e ele adicionado ao coeficiente $\alpha_{6}$ $(-0,3924+0,1228=-0,2616)$ são negativos, o que indicam que, no ano que ocorre mudança da empresa de auditoria responsável, as demonstrações contábeis das companhias abertas brasileiras reportam resultados mais conservadores. 
No que se refere ao atraso na emissão do relatório de auditoria independente, a literatura descreve que o maior tempo na emissão indica menor qualidade da informação contábil. Assim, como nas análises anteriores, a inclusão de uma proxy para indicar o tempo entre o final do ano-competência e a data de emissão do relatório de auditoria independente, alterou os coeficientes de mensuração e o comportamento dos números contábeis $\left(\alpha_{2}\right.$ e $\left.\alpha_{3}\right)$. Nessa análise, os coeficientes são estatisticamente significantes, sendo que os sinais preditivos foram invertidos em relação ao modelo original. Já os parâmetros dos coeficientes $\alpha_{6}$ e $\alpha_{7}$ assumem sinal positivo e negativo, respectivamente, e ambos são estatisticamente significativos. Mas a soma desses coeficientes é baixa $(-0,0048)$, tornando-se insignificante.

Um dos temas mais discutidos no meio acadêmico e profissional refere-se ao prejuízo na independência, quando a firma de auditoria presta outros tipos de serviços ao cliente auditado. Analisando-se os parâmetros descritos na Tabela 7, verificaram-se que os coeficientes $\alpha_{2}$ e $\alpha_{3}$ não sofreram variações significativas e permaneceram conforme esperado para o modelo original. Entretanto, os coeficientes $\alpha_{6}$ e $\alpha_{7}$ não são significativamente diferentes de zero, o que indica que a prestação de serviços de não auditoria não afeta, significativamente, o nível de conservadorismo das demonstrações contábeis das companhias abertas brasileiras.

Tabela 7

Relação do Conservadorismo com o Tempo de Relacionamento (Tenure), Rodizio e Audit Delay amanho da Firma de Auditoria e o Tipo de Cliente

\begin{tabular}{|c|c|c|c|c|c|c|c|c|}
\hline & \multicolumn{2}{|c|}{ Original } & \multicolumn{2}{|c|}{$\begin{array}{l}\text { Serviços de Não } \\
\text { Auditoria (NAS) }\end{array}$} & \multicolumn{2}{|c|}{$\begin{array}{l}\text { Importância do } \\
\text { Cliente (IMPCLI) }\end{array}$} & \multicolumn{2}{|c|}{$\begin{array}{c}\text { Especialização } \\
\text { da empresa de } \\
\text { auditoria (AUDEXP) }\end{array}$} \\
\hline & coeficiente & p-value & coeficiente & $p$-value & coeficiente & p-value & coeficiente & $p$-value \\
\hline Interceptor & $-0,018$ & $-0,031$ & 0,882 & $-0,031$ & 0,882 & 0,882 & $-0,007$ & 0,973 \\
\hline$D \Delta N I_{i t-1}$ & 0,064 & 0,067 & 0,023 & 0,067 & 0,023 & 0,023 & 0,072 & 0,019 \\
\hline$\Delta N I_{i t-1}$ & 0,542 & 0,544 & 0,127 & 0,544 & 0,127 & 0,127 & 0,543 & 0,128 \\
\hline$\Delta N I_{i t-1} * D \Delta N I_{i t-1}$ & $-0,971$ & $-0,967$ & 0,043 & $-0,967$ & 0,043 & 0,043 & $-0,966$ & 0,043 \\
\hline$C_{i t}$ & & 0,062 & 0,015 & 0,062 & 0,015 & 0,015 & 0,056 & 0,121 \\
\hline$C_{i t}{ }^{*} D \Delta N I_{i t-1}$ & & $-0,084$ & 0,019 & $-0,084$ & 0,019 & 0,019 & $-0,067$ & 0,077 \\
\hline$C_{i t}{ }^{*} \Delta N I_{i t-1}$ & & $-0,666$ & 0,078 & $-0,666$ & 0,078 & 0,078 & $-0,702$ & 0,130 \\
\hline$C_{i t} * \Delta N I_{i t-1} * D \Delta N I_{i t-1}$ & & $-0,021$ & 0,963 & $-0,021$ & 0,963 & 0,963 & 0,850 & 0,171 \\
\hline $\operatorname{LnAT}_{i t-1}$ & $-0,007$ & $-0,008$ & 0,634 & $-0,008$ & 0,634 & 0,634 & $-0,009$ & 0,626 \\
\hline DLoss $_{i t-1}$ & $-0,109$ & $-0,111$ & 0,000 & $-0,111$ & 0,000 & 0,000 & $-0,111$ & 0,000 \\
\hline$R O A_{i t-1}$ & 0,031 & 0,030 & 0,016 & 0,030 & 0,016 & 0,016 & 0,030 & 0,015 \\
\hline$A L A V_{i t-1}$ & 0,003 & 0,003 & 0,740 & 0,003 & 0,740 & 0,740 & 0,003 & 0,743 \\
\hline$F C O_{i t-1}$ & 0,272 & 0,281 & 0,058 & 0,281 & 0,058 & 0,058 & 0,283 & 0,056 \\
\hline$R^{2}$ & 0,291 & 0,294 & & 0,294 & & & 0,293 & \\
\hline$R^{2}$ ajustado & 0,277 & 0,277 & & 0,277 & & & 0,277 & \\
\hline F-statistic & 20,088 & 20,224 & 0,000 & 20,224 & 0,000 & 0,000 & 17,954 & 0,000 \\
\hline White Test & 23,849 & 7,426 & 0,000 & 7,426 & 0,000 & 0,000 & & \\
\hline Serial Correlation LM & 83,722 & 81,114 & 0,000 & 81,114 & 0,000 & 0,000 & & \\
\hline Jarque-Bera & $1,4 \mathrm{E}+7$ & $1,1 \mathrm{E}+7$ & 0,000 & $1,1 \mathrm{E}+7$ & 0,000 & 0,000 & $1 \mathrm{E}+07$ & 0,000 \\
\hline Observações & 1.998 & 1.871 & & 1.871 & & & 1.947 & \\
\hline
\end{tabular}

Modelo adaptado (equação 2) $\Delta N I_{i t}=a_{0}+a_{1} D \Delta N I_{i t-1}+a_{2} \Delta N I_{i t-1}+a_{3} \Delta N I_{i t-1 *} D \Delta N I_{i t-1}+a_{4} C_{i t}+a_{5} C_{i t t^{*}} D \Delta N I_{i t-1}+a_{6} C_{i t t^{*}} \Delta N I_{i t-1}+a_{7} C_{i t} \Delta N I_{i t-1 *} D \Delta N I_{i t-1}+\varepsilon_{i t} E m$ que: $\Delta N l_{i t}=$ variação no lucro líquido da empresa $i$ do ano $t-1$ para o ano $t$ ponderada pelo ativo total no início do ano $t ; \Delta N I_{i t-1}=v a r i a c ̧ a ̃ o$

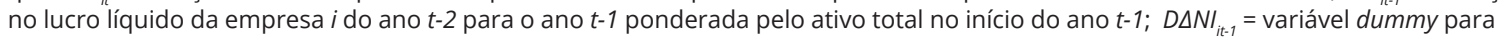
indicar se existe variação negativa no lucro líquido da empresa $i$ do ano $t-1$ para o ano $t$, assumindo valor 1 se $\Delta N I_{i t}<0$, e 0 nos demais casos; $C_{i t}=$ característica da qualidade de auditoria na empresa $i$ no ano $t ; L n A T_{i t}=$ logaritmo do ativo total da firma auditada; $D L o s s_{i t}=$ variável dummy para indicar se o lucro líquido da empresa $i$ no ano $t$ foi negativo, assumindo valor 1 se $N I_{i t}<0$, e 0 nos demais casos; $R O A_{i t}=$ retorno sobre ativos da firma auditada da empresa $i$ no ano $t ; A l a v_{i t}=$ alavancagem da firma da $i$ no ano $t ;\left(F C O_{i t}\right)=$ fluxo de caixa operacional da empresa $i$ no ano $t$ ponderada pelo ativo total no início do ano $t$. 
Ainda referente à preocupação com a independência da firma de auditoria, analisou se a importância do cliente afeta o comportamento conservador dos números contábeis reportados pelas companhias abertas no mercado de capitais brasileiro. De acordo com a Tabela 7, verifica-se que o coeficiente $\alpha_{2}$ é positivo e não significativamente diferente de zero, enquanto $\alpha_{3}$ é negativo e significativo, conforme preditivo para o modelo original. Mas os coeficientes $\alpha_{6}$ e $\alpha_{7}$, que analisam a importância do cliente, não são significativos, implicando que essa característica não afeta o nível de conservadorismo das demonstrações contábeis das companhias abertas brasileiras.

No que tange à competência da auditoria, analisou-se aqui a especialização da firma de auditoria e se essa característica afeta a qualidade da informação contábil, especificamente, o conservadorismo contábil. As evidências descritas na Tabela 7 indicam que os coeficientes $\alpha_{2}$ e $\alpha_{3}$ são, respectivamente, positivo e negativo, sendo que somente o último é significativo, e confirmam o esperado pela especificação do modelo. Por outro lado, os coeficientes $\alpha_{6}$ e $\alpha_{7}$, que buscam captar a especialização, ou não, da firma de auditoria, não apresentam coeficientes significativos. Assim, esses resultados sugerem que a maior especialização de auditoria no ramo de atividade do cliente não influencia o comportamento conservador dos números contábeis reportados pelas empresas brasileiras.

Com relação aos pressupostos da análise de regressão, o da Linearidade foi atendido adequadamente, bem como em relação à Exogeneidade, pois os regressores das especificações dos modelos não possuem forte correlação com os resíduos da regressão (Greene, 2003). A apresentação da análise de correlação foi suprimida do texto devido à limitação do número de páginas. No que se refere à homoscedasticidade, foi utilizado o estimador de White para obter o erro-padrão robusto em relação à heteroscedasticidade. Por outro lado, as estatísticas apresentadas nas Tabelas 5 a 7 indicam que os resíduos não têm distribuição normal e existe presença de autocorrelação na amostra desta pesquisa, mas esses podem ser relaxados nas inferências sobre os parâmetros dos modelos, pois, segundo Wooldridge (2002) e Greene (2003), seus coeficientes são consistentes e não viesados assintoticamente, mas deixam de ser os melhores estimadores lineares não viesados. Por fim, o grau de multicolinearidade, pelo fator de inflação da variância não é considerado problemático no modelo empregado.

O coeficiente de determinação ajustado ( $R^{2}$ ajustado) variou entre 0,27 a 0,58 , dependendo da característica da qualidade da auditoria analisada. Portanto, no que se refere ao poder preditivo das equações estimadas, pode-se considerar que elas apresentam um adequado ajustamento do comportamento conservador dos resultados contábeis. Assim exposto, os resultados aqui são relevantes para explicar a relação de causa e efeito de eventos passados, porém não devem ser utilizados para estimar ou prever fenômenos futuros. Devido à limitação de tamanho do trabalho, a apresentação mais detalhada dessas informações não pode ser evidenciada neste texto.

\section{Considerações Finais}

Esta pesquisa buscou analisar se essas características (ou atributos) da qualidade da auditoria afetam a qualidade das informações contábeis, especificamente, o conservadorismo contábil. Inicialmente verificou-se que os resultados da pesquisa sugerem que os números contábeis reportados pelas companhias abertas brasileiras possuem comportamento conservador.

Uma das hipóteses de pesquisa trata sobre o tamanho da firma de auditoria e o nível de conservadorismo. Com base nas evidências apresentadas, pode-se confirmar que o nível de conservadorismo contábil é maior nos números reportados pelas empresas auditadas pelas maiores firmas de auditoria independente (Big) do que pelas menores. Assim, sugere-se que as maiores firmas de auditoria independente, normalmente, denominadas de Big Four, apresentam maior qualidade de auditoria e que afetam positivamente o nível de conservadorismo. As evidências apresentadas neste trabalho apontam que o comitê de auditoria não influenciou o conservadorismo dos números contábeis. Assim, esse mecanismo de governança corporativa não contribui para a qualidade da auditoria e, consequentemente, para a gestão das firmas. 
Um dos pontos amplamente discutidos nos vários fóruns acadêmicos e profissionais é sobre o tempo de prestação de serviços de auditoria. Os resultados apresentados na análise estatística indicam que o conservadorismo contábil é fortemente afetado pelo número de anos contínuos em que a companhia aberta é auditada pela mesma firma de auditoria. Adicionalmente, verificou-se que o nível de conservadorismo é maior no ano em que ocorre a mudança da firma de auditoria responsável. Diante desse cenário, sugere-se que o maior tempo de prestação de serviços de auditoria afeta negativamente a qualidade dos serviços de auditoria, pois, provavelmente, interfere no relacionamento do auditor com o cliente.

No que se refere à relação entre o tempo de emissão do relatório da auditoria independente e o conservadorismo contábil, as evidências apresentadas neste trabalho confirmam que o maior espaço de tempo entre a data das demonstrações contábeis e a data de emissão do relatório de auditoria independente é inversamente relacionado ao conservadorismo contábil. Assim, sugere-se que o atraso na emissão do relatório da auditoria pode ser um indicativo de menor qualidade nos resultados contábeis, nesse estudo menor conservadorismo nos números contábeis.

Sobre a influência dos serviços de não auditoria, prestadas pelas próprias firmas responsáveis pela auditoria, os resultados demonstram que o nível de conservadorismo contábil não é afetado negativamente por essas relações contratuais. Entretanto, também, não existem evidências de que a prestação de outros serviços pela auditoria responsável aumente o conhecimento sobre os negócios da companhia auditada.

Outra hipótese levantada é de que a importância do cliente prejudica o relacionamento entre o auditor e a empresa auditada e, por conseguinte, afeta negativamente a qualidade das informações contábeis e da auditoria. Porém, as evidências encontradas não confirmam a tese de que quanto mais importante for o cliente, menor a qualidade dos serviços de auditoria e da informação contábil reportada por ele. Finalmente, a última hipótese, este trabalho apresenta evidências que não confirmam que a maior especialização no ramo de conhecimento de atividade do cliente influencia a qualidade da auditoria.

Com base na literatura corrente, utilizaram-se outras variáveis contábeis empregadas nas pesquisas empíricas sobre auditoria. Os resultados apresentados nesta pesquisa indicam que alguma delas, como o tamanho da empresa auditada, perdas contábeis ou fluxo de caixa operacional, podem ser relevantes para a devida estimação dos parâmetros de interesse da pesquisa. Resumidamente, portanto, os resultados indicam que o conservadorismo contábil é afetado diretamente pelo tamanho da firma de auditoria, enquanto que tempo de prestação de serviços de auditoria e o atraso na emissão do relatório da auditoria independente possuem uma relação inversa com a qualidade da informação contábil.

De forma geral, os resultados desta pesquisa podem contribuir para a compreensão sobre a eficiência de alguns instrumentos de governança corporativa, em especial, quando aplicados em empresas que atuam em mercados emergentes, como o Brasil.

Observa-se, nos resultados apresentados, que a criação do comitê de auditoria não contribuiu para a melhoria da qualidade das informações reportadas, em especial, o conservadorismo. Dessa forma, pode-se questionar se esse mecanismo de governança amplia a independência dos auditores contratados.

Outro ponto discutível é sobre os benefícios e prejuízos ocorridos pelo rodízio da empresa de auditoria (ou auditor responsável). Os resultados aqui apresentados destacam que o conservadorismo é afetado, significativamente, pelo rodízio da firma de auditoria e decresce ao longo do tempo de relacionamento entre o cliente e firma de auditoria. Desse modo, os resultados apontam que o rodízio da firma de auditoria é um mecanismo eficiente para a melhoria da qualidade dos números reportados, apesar da possível perda de conhecimento das atividades do cliente.

Apesar ter sido um dos principais pontos levantados quando dos escândalos financeiros no início deste século, na amostra desta pesquisa, a prestação de serviços de não auditoria e a importância do cliente não afetaram a qualidade dos números contábeis.

Não obstante, cabe salientar que este trabalho apresenta algumas limitações, como a utilização de proxies para mensurar cada uma das características da qualidade da auditoria, que podem, ou não, medir adequadamente o atributo analisado. Além disso, este trabalho avaliou exclusivamente a relação entre as características da auditoria e o conservadorismo contábil. Entretanto, existem outros atributos descritos 
na literatura que representam fortemente a qualidade dos números contábeis reportados pelas empresas.

Por fim, pode-se sugerir como pesquisas futuras a ampliação da amostra de empresas com outros tipos de estrutura jurídica societária, como as companhias fechadas ou sociedades limitadas. Pode-se, também, avaliar outros atributos da qualidade da auditoria, ou mesmo, da qualidade das informações contábeis, tais como gerenciamento de resultados, value relevance, etc. Outras formas de estimações estatísticas também seriam relevantes para apurar de forma mais adequada os parâmetros dos modelos nas pesquisas que versam sobre a auditoria. Além disso, utilizar-se de outros métodos de coleta de dados, tais como, questionários e entrevistas com analistas, auditores e profissionais envolvidos com o trabalho de auditoria, para verificar em que esses profissionais contribuem para a melhor qualidade das informações.

Espera-se que esta pesquisa contribua para a melhor compreensão dos diversos fatores que afetam a qualidade da auditoria, bem como o relacionamento desses com o conservadorismo contábil presente nas demonstrações contábeis. Espera-se também que, de alguma forma, este trabalho auxilie o desenvolvimento dos novos estudos sobre as características das informações contábeis e da qualidade da auditoria no Brasil.

\section{Referências}

Almeida, J. E. F. de, \& Almeida, J. C. G. de. (2009). Auditoria e earnings management: estudo empírico nas empresas abertas auditadas pelas big four e demais firmas de auditoria. Revista Contabilidade \& Finanças, 20(50), p.62-74.

Azevedo, F. B., \& Costa, F. M. (2012) Efeito da troca da firma de auditoria no gerenciamento de resultados das companhias abertas brasileiras. RAM Revista de Administração do Mackenzie, 13(5), 65-100.

Ball, R., Kothari, S. P., \& Robin, A. (2000).The effect of international institutional factors on properties of accounting earnings. Journal of Accounting and Economics, 29(1), 1-51.

Ball, R., \& Shivakumar, L. (2005). Earnings quality UK private firms: comparative loss recognition timeliness. Journal of Accounting and Economics, 39(1), 83-128.

Barth, M. E., Landsman, W. R., \& Lang, M. H. (2008). International accounting standards and accounting quality. Journal of Accounting Research, 46(3), 467-498.

Balsam, S.; Krishnan, J.; \& Yang, J. S. (2003). Auditor industry specialization and earnings quality. Auditing: A Journal of Practice and Theory, 22(2), 71-97.

Basu, S. (1997). The conservatism principle and the asymmetric timeliness of earnings. Journal of Accounting and Economics, 24(1), p.3-37.

Behn, B., Choi, J. H., \& Kang, T. (2008). Audit quality and properties of analyst earnings forecasts. The Accounting Review, 83(2), 327-349.

Beuren, I. M. (Org.). (2006). Como elaborar trabalhos monográficos em contabilidade: teoria e prática (3a ed.) São Paulo: Atlas.

Braunbeck, G. (2010). O. Determinantes da qualidade das auditorias independentes no Brasil. Tese de doutorado, Universidade de São Paulo, São Paulo, SP, Brasil.

Burgstahler, D. C., Hail, L., \& Leuz, C. (2006). The importance of reporting incentives: earnings management in European private and public firms. The Accounting Review, 81(5), 983-1016.

Chaney, P., Jeter, D., \& Shivakumar, L. (2004). Self-selection of auditors and audit pricing in private firms. The Accounting Review, 79(1), 51-72.

Chin, W., Douthett, E. B., Jr., \& Lisic, L. L. (2012). Client importance and audit partner independence. Journal of Accounting and Public Policy, 31(3), p.320-336. 
Chung, H., \& Kallpur, S. (2003). Client importance, nonaudit services and abnormal accruals. The Accounting Review, 78(4), 931-955.

Cupertino, C., \& Martinez, A. L. (2008). Qualidade da auditoria e earnings management risk assessment através do nível de accruals discricionários. Contabilidade Vista \& Revista, 19(3), 69-93.

DeAngelo, L. E. (1981). Auditor size and auditor quality. Journal of Accounting and Economics, 3(3), p.183199.

DeAngelo, L. E. (1982). Mandated successful efforts and auditor choice. Journal of Accounting and Economics, 4(3), p.171-203.

Dechow, P. M., \& Schrand, C. M. (2004). Earnings quality. Virginia: CFA Institute.

Dechow, P. M., Ge, W., \& Schrand, C. M. (2010). Understanding earnings quality: a review of proxies, their determinants and their consequences. Journal of Accounting and Economics, 50(2-3), 344-401.

DeFond, M. L.,\& Subramanyam, K. R. (1998). Auditor changes and discretionary accruals. Journal of Accounting and Economics, 25(1), 35-67.

Fargher, N., Taylor, M. H., \& Simon, D. T. (2001). The demand for auditor reputation across international markets for audit services. International Journal of Accounting, 36(4), 407-421.

Fortin, S. \& Pittman, J.A. (2007). The role of auditor choice in debt pricing in private firms. Contemporary Accounting Research, 24(3), 859-896.

Francis, J. R., \& Ken, B. (2006). Disclosure of fees paid to auditors and the market valuation of earnings surprises. Review of Accounting Studies, 11(4), 495-523.

Francis, J. R., \& Wang, D. (2008). The joint effect of investor protection and Big 4 audits on earnings quality around the world. Contemporary Accounting Research, 25(1), 157-191.

Gaver, J. J., \& Paterson, J. S. (2001). The association between external monitoring and earnings management in the property-casualty insurance industry. Journal of Accounting Research, 39(2), 269-282.

Ghosh, A, \& Moon, D. (2005). Auditor tenure impair audit quality. The Accounting Review, 80(2), 585-612.

Greene, W. H. (2003). Econometric analysis (5th ed.) New Jersey: Prentice Hall.

Holthausen, R. W., \& Watts, R. L. (2001). The relevance of the value-relevance literature for financial accounting standard setting. Journal of Accounting and Economics, 31(1-3), 3-75.

International Accounting Standards Board. (2013). Discussion Paper DP/2013/1 A review of the conceptual framework for financial reporting. Londres: IFRS Foundation.

Iudícibus, S. de. (2004). Teoria da contabilidade. (7a ed.). São Paulo: Atlas.

Jenkins, D. S., \& Velury, U. (2008). Does auditor tenure impact the reporting of conservative earnings. Journal of Accounting and Public Policy, 27(2), 115-132.

Koch, C. W., Weber, M., \& Wüstemann, J. (2012). Can auditors be independent? experimental evidence on the effects of client type. European Accounting Review, 21(4), 797-823.

Krishnan, G. V., \& Yang, J. S. (2009). Recent trends in audit report and earnings announcement lag. Accounting Horizons, 23(3), 265-288.

Lennox, C. S.; Francis, J. R., \& Wang, Z. (2012). Selection models in accounting research. The Accounting Review, 87(2), 589-616.

Li, D. (2010). Does auditor tenure affect accounting conservatism? further evidence. Journal of Accounting and Public Policy, 29(3), 226-241.

Lobo, G. J., \& Zhou, J. (2005). To swear early or not swear early? an empirical investigation of factors affecting CEO's decisions. Journal of Accounting and Public Policy, 24(2), 153-160. 
Lopes, A. B., \& Martins, E. (2005). Teoria da contabilidade: uma nova abordagem. São Paulo: Atlas.

Myers, J., Myers, L., \& Omer, T. (2003). Exploring the term of the auditor-client relationship and the quality of earnings: A case for mandatory auditor rotation. The Accounting Review, 78(3), 779-799.

Ng, P. P. H., \& Tai, B. Y. K. (1994). An empirical examination of the determinants of audit delay in Hong Kong. British Accounting Review, 26(1), 43-59.

Nikolaev, V. V. (2010). Debt convenants and accounting conservatism. Journal of Accounting Research, 48(1), 137-175.

O’Keefe, T. B., King, R. D., \& Gaver, K. M. (1994). Audit fees, industry specialization, and compliance with GAAS reporting standards. Auditing: A Journal of Practice and Theory, 13(1), 41-55.

Paulo, E., Antunes, M. T. P., \& Formigoni, H. (2008). Conservadorismo contábil nas companhias abertas e fechadas brasileiras. RAE Revista de Administração de Empresas, 48(3), 46-60.

Penman, S. H. \& Zhang, X. J. (2002). Accounting conservatism and the quality of earnings, and stock returns. The Accounting Review, 77(2), 237-264.

Ruddock, C., Taylor, S. J., \& Taylor, S. L. (2006). Nonaudit services and earnings conservatism: is auditor independence impaired? Contemporary Accounting Research, 23(3), 701-746.

Sun, J. A., \& Liu, G. (2011). Industry specialist auditors, outsider directors, and financial analysts. Journal of Accounting and Public Policy, Baltimore, 30(4), 367-382.

Sunder, S. (1997). Theory of accounting and control. Cincinnati: South-Western Publishing.

Watts, R. L. (2003a). Conservatism in accounting part I: explanations and implications. Accounting Horizons, 17(3), 207-221.

Watts, R. L. (2003b). Conservatism in accounting part II: evidence and research opportunities. Accounting Horizons, 17(3), 207-221.

Weber, J., \& Willenborg, M. (2003). Do expert informational intermediaries add value? Evidence from auditors in microcap initial public offerings. Journal of Accounting Research, 41(4), 681-720.

Wooldridge, J. M. (2002). Introductory econometrics: a modern approach. (2nd ed). Ohio: South-Western College Pub. 